\title{
RANCANG BANGUN SISTEM INFORMASI GEOGRAFIS UNTUK POTENSI TERNAK PADA KAB.PASURUAN BERBASIS WEB
}

\author{
Dhiky Wardany Yacub, Hani Zulfia Zahro', Nurlaily Vendyansyah \\ Program Studi Teknik Informatika S1, Fakultas Teknologi Industri \\ Institut Teknologi Nasional Malang, Jalan Raya Karanglo km 2 Malang, Indonesia \\ 1618102@scholar.itn.ac.id
}

\begin{abstract}
ABSTRAK
Kab.Pasuruan merupakan salah satu daerah di wilayah provinsi Jawa Timur dengan tingat komoditas perternakan yang begitu pesat, Adapun potensi ternak yang bisa dijumpai diantaranya sapi potong, sapi perah, kerbau, kuda, kambing, domba, ayam buras, ayam petelur, ayam pedaging, itik, angsa, puyuh, kelinci, anjing. dengan tingkat produksi daging yang sering dijumpai pada Kab.Pasuruan diantaranya sapi, kambing, domba, ayam pedaging, ayam petelur, ayam buras, itik, susu, dan telur. Di Kab.Pasuruan juga terdapat budidaya japung, sawah tambak, mina padi, tambak sebagai mata pencaharian bagi sejumlah masyarakat yang ada pada Kab.Pasuruan. Dengan melihat hal tersebut jumlah besarnya usaha ternak menjadikan Pasuruan sebagai penghasil ternak terbaik, akan tetapi masyarakat kurang mendapatkan informasi terkait wilayah-wilayah dengan tingkat populasi ternak maupun produksi ternak yang semakin meningkat, dan juga para pengusaha ternak yang mengelola perternakan mereka tidak bisa mengalokasikan dan mengkontribusi hasil ternak mereka dengan baik dan benar.

Melihat situasi pada Kab.Pasuruan dengan tingkat populasi, produksi maupun budidaya yang semangkin meningkat maka dari itu dibutuhkannya sistem informasi geografis untuk pemetaan potensi ternak pada Kab.Pasuruan guna untuk membantu pencarian data atau potensi ternak pada suatu wilayah dengan tingkat potensi ternak yang tinggi.

Hasil dari pemetaan potensi ternak pada Kab.Pasuruan ini berupa tampilan website yang didalamnya terdapat peta Kab.Pasuruan beserta atribut peta kecamatan. Pada peta kecamatan yang sudah di digitasikan melalui quantum gis dan di export ke website menghasilkan peta Kab.Pasuruan dan atribut tiap kecamatan. Adapun dengan pencarian melalui beberapa fungsi pencarian diantara lain pencarian populasi ternak, produksi ternak dan juga budidaya yang menghasilkan data dari tiap-tiap komoditas dari tiap-tiap atribut pencarian. Hasil yang terakhir adalah dengan implementasi dan pengujian pada sistem yang telah dibuat.
\end{abstract}

Kata Kunci : Sistem Informasi Geografis, Pemetaan, Potensi Ternak, Kab.Pasuruan, website

\section{PENDAHULUAN}

Kab.Pasuruan merupakan daerah dengan tingkat perkembangan khususnya dalam bidang peternakan. Keberadaan peternakan tersebut sangatlah penting bagi sejumlah masyarakat yang ada pada Kab. Pasuruan dengan beberapa lokasi kecamatan yang ada pada kab.Pasuruan diantara lain kecamatan Nguling, Pandaan, Purwosari, Wonorejo, Keraton, dan Kajayan. Keberadaan peternakan sangat penting di Kab.Pasuruan, meskipun masyarakat Kab.Pasuruan tinggal di wilayah Kab.Pasuruan dan mudah mengakses akan tetapi masyarakat sangatlah kurang informasi mengenai lokasi dari daerah-daerah dengan tingkat peternakan yang cukup tinggi. Adapun peternakan yang bisa dijumpai pada wilayah Kab.Pasuruan di antaranya adalah sapi potong, sapi perah, kerbau, kuda, kambing, domba, ayam petelur, itik, angsa, puyuh, kelinci, anjing. Melihat situasi pada Kab.Pasuruan dengan tingkat populasi, produksi maupun budidaya yang semangkin meningkat maka dari itu dibutuhkannya sistem informasi geografis untuk pemetaan potensi ternak pada Kab.Pasuruan guna untuk membantu pencarian data atau potensi ternak pada suatu wilayah dengan tingkat potensi ternak yang tinggi.

\section{TINJAUAN PUSTAKA}

\subsection{Penelitian Terdahulu}

ditahun 2017 Ari melakukan penilitian terkait dengan Pengembangan sistem informasi geografis berbasis web untuk menampilkan halaman profil, potensi kota saat ini masih sangat terbatas, khususnya di wilayah kota Malang. Kota Malang merupakan salah satu kota yang maju yang memiliki banyak sekali potensi kota baik dari alam maupun buatan. Sampai saat ini masyarakat kesulitan mencari suatu lokasi service center di kota Malang. Hal ini disebabkan karena data masih disimpan dalam bentuk penyimpanan arsip maupun komputer secara manual. Oleh sebab itu Sistem Informasi Geografis Service Center ini sangat diperlukan demi mengenfesiensi waktu dan mempermudah dalam input data. [1]

Pada tahun 2018 Pranoto dan kawan-kawan melakukan penelitian terkait dengan masyarakat di Indonesia di dukung dengan pemerintah meningkatkan pelayanan dalam bidang kesehatan diantarranya dengan mmbentuk suatu badan yang berfungsi untuk mendukung ketahanan kesehatan nasional yang disebut dengan BPJS (badan penyelenggara jaminan sosial). Penggunaan media 
website sebagai media dipilih Karena maraknya pengguna internet aktif di Indonesia yang mendudukkan Indonesia di peringkat ke-6 terbesar di dunia. Pada pengujian fungsional, fungsi $100 \%$ sudah sesuai dengan kebutuhan aplikasi baik pada browser desktop maupun mobile serta dari $75 \%$ pengguna menilai aplikasi ini bermanfaat Dari hasil pengujian efisiensi waktu terlihat bahwa untuk penggunaan aplikasi desktop browser memiliki efisiensi waktu yang dapat dihemat rata-rata sebesar 87,7 \% dan 75 $\%$ untuk mobile browser. [2]

Di tahun yang sama Julkifli melakukan sebuah penelitian tentang upaya untuk meningkatkan pelayanan khususnya di wilayah kecamatan woja tersebut maka pemerintah Kecamatan Woja melakukan berbagai tindakan atau usaha untuk dapat memberikan pelayanan yang sesui untuk masyarakat khususnya masyarakat yang berada di wilayah Kecamatan Woja Kabupaten Dompu salah satu usaha yang di lakukan oleh pemerintah kecamatan woja yaitu dengan membangun sistem pemetaan yaitu Sistem Informasi Geografis Kecamatan Woja Kabupaten Dompu Nusa Tenggara Barat.[3]

Pada tahun 2019 Messy melakukan penilitian mengenai Sistem Informasi Geografis Pemetaan Daerah Perkebunan, Penyajian data potensi komoditi perkebunan saat ini masih banyak disajikan dalam laporan statistik tahunan di setiap daerah di Indonesia. Hal ini juga yang terjadi di wilayah provinsi Kalimantan Tengah Sehubungan dengan hal tersebut, maka disediakan Sistem Informasi Geografis Pemetaan Daerah Perkebunan dengan adanya Sistem Informasi Geografis Dinas Perkebunan Kalimantan Tengah dapat mengelola data lapangan secara lebih cepat dan terperinci dengan baik. [4]

\subsection{Sistem Informasi Geografis}

Sistem Informasi Geografis (SIG) atau Geographic Information System (GIS) adalah sistem informasi khusus yang mengelola data dengan informasi spasial yang merupakan rujukan spasial. Singkatnya, sistem informasi geografis adalah sistem komputer yang dapat digunakan untuk membuat, menyimpan, mengelola, dan menampilkan informasi yang relevan secara geografis. Misalnya data diidentifikasi berdasarkan lokasinya dalam database. Teknologi Sistem Informasi Geografis digunakan untuk investigasi ilmiah, manajemen sumber daya, perencanaan pembangunan, pemetaan dan perencanaan rute. Misalnya perencana dapat menggunakan GIS untuk menghitung waktu tanggap darurat ketika bencana alam terjadi dengan cepat dan sebagainya.[5]

\subsection{Leaflet}

Leaflet merupakan library javascript open source yang berguna untuk membangun aplikasi peta interaktif berbasis web. Leaflet support dengan platform mobile dan platform desktop, HTML5 dan
CSS3 serta OpenLayer dan Google Maps API yang merupakan library javascript untuk membangun aplikasi peta yang sangat popular saat ini. [6]

\subsection{Pemetaan}

Peta merupakan suatu gambaran yang ada dari permukaan bumi ini yang digambarkan di bidang datar dalam proyeksi tertentu, Peta disajikan dengan cara yang bermacam-macam. Ada peta konvesional hingga peta yang dapat tampil di sistem proyeksi.[7]

\subsection{Data Spasial Dan Non Spasial}

Data spasial bisa dikatakan sebagai gambaran dari permukaan bumi ke dalam bentukan seperti garis, titik atau polygon yang keudian bisa disebut dengan peta. Sedangkan data non spasial adalah data yang berisi tentang angka-angka yang biasanya digunakan untuk menjelaskan apa isi dari peta itu. Data non spasial bisa berasal dari data sensus, survey atau data data lain yang berbentuk angka.[8]

\subsection{Komoditas Peternakan Di Kab.Pasuruan}

Kawasan pengembangan sapi potong di kabupaten pasuruan meliputi wilayah kecamatan purwosari, purwodadi, pandaan, prigen, sukorejo kejayan, dari wilayah-wilayah tersebut sampai dengan tahun 2008 produksi daging yang dihasilkan mencapai 84.222 ton /th. [9]

\subsection{Populasi Ternak}

Dinas Peternakan dan Ketahanan Pangan Kabupaten Pasuruan mengimbau masyarakat agar pintar dalam memilih hewan kurban yang sehat. Sehingga dagingnya berkualitas dan layak dikonsumsi warga. Himbauan tersebut disampaikan Kepala Dinas Peternakan dan Ketahanan Pangan Kabupaten Pasuruan, Drh Irianto melalui Kabid Keswan (Kesehatan Hewan), Drh Ainur Alfiah.[10]

\subsection{Produksi Ternak}

Realisasi total produksi susu perah mencapai 115 persen, Realisasi produksi susu itu melebihi tahun 2017, lantarannya hasil capaian mencapai sekitar 103.157 ton. Produksi susu sapi perah berada merata di 24 Kecamatan, Kabupaten Pasuruan.[11]

\subsection{Budidaya}

Ternak-ternak yang ada sekarang bermula dari hewan-hewan yang liar. Karena adanya kepentingan manusia terhadap hewan-hewan liar tersebut, maka manusia melakukan penjinakan (domestikasi) agar menjadi hewan piara (ternak) yang berguna dan bermanfaat bagi manusia. [12]

\section{METODE PENELITIAN}

\subsection{Blok Diagram Sistem}

Blok diagram adalah diagram dari sebuah sistem, di mana data spasial pasuruan, data atribut pasuruan, data produksi, dan data budidaya sebagai inputan ke dalam sistem, digitasi peta pasuruan, 
menganalisa data atribut kedalam tabel atribut dengan contoh daerah yang berpotensi banyaknya peternakan, menganalisa data populasi dalam bentuk tabel, populasi, dan juga budidaya sebagai pemroses dalam sistem, tampilan berupa gambar digital peta Kab.Pasuruan, informasi atribut dari beberapa wilayah Kab.Pasuruan, informasi dari daerah populasi, produksi, dan budidaya sebagai output. Ilustrasi sistem ditunjukan pada Gambar 2.

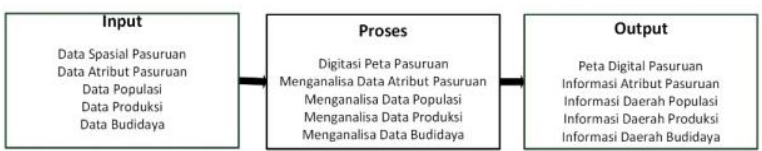

Gambar 2. Blok diagram Sistem

\subsection{Flowchart Sistem}

Flowchart sistem ini menjelaskan proses berjalananya aplikasi seperti ditunjukkan pada Gambar 3.

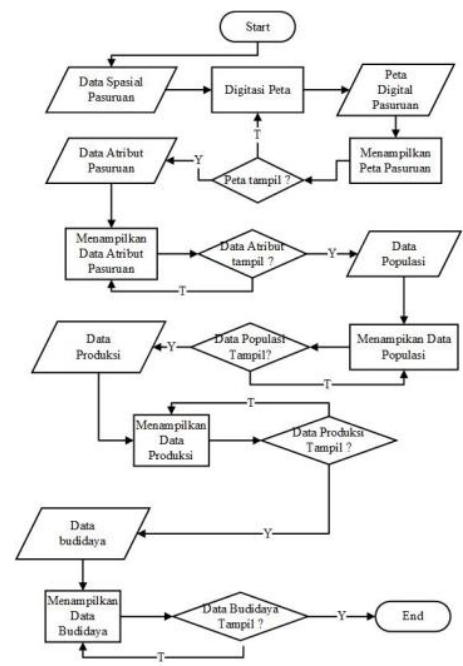

Gambar 3 Flowchart sistem

Berdasarkan flowchart pada Gambar 3, sistem diawali dengan Start kemudian Input Data spasial Pasuruan, selanjutnya dari data tersebut dilakukan digitasi peta dari data spasila tadi, setelah dilakukan digitasi tadi maka hasilnya peta digital Kab.Pasurun. Kemudian di proses untuk menampilkan peta pasuruan, jika peta tidak muncul maka Kembali ke proses menampilkan peta pasuruan dan jika muncul maka melakukan inputan data atribut pasuruan, kemudian di proses menampilkan data atribut pasuruan, jika data atribut tidak tampil maka Kembali ke proses menampilkan data atribut pasuruan dan jika berhasil maka lanjut ke inputan data populasi, dan melakukan pemrosesan untuk menampilkan data populasi, jika data populasi tidak muncul maka Kembali ke proses menampilkan data populasi dan jika berhasil menampilkan data populasi maka lanjut ke inputan data produksi, kemudian dari data produksi di proses datanya untuk di tampilkan, jika tidak maka Kembali ke proses menampilkan data produksi dan jika berhasil menampilkan data produksi maka masuk ke inputan data budidaya kemudian diproses menampilkan data budidaya, jika tidak maka Kembali ke proses menampilkan data budidaya dan jika berhasil maka selesai atau end.

\section{HASIL DAN PEMBAHASAN}

\subsection{Pembuatan Peta Pada Quantum Gis}

Pada pembuatan peta menggunakan Quantum Gis, peta yang di buat merupakan peta Kab.Pasuruan dengan atribut peta kecamatan pada Kab.Pasuruan dengan ketentuan warna pada tiap gambar peta yang di tunjukan pada gambar 4

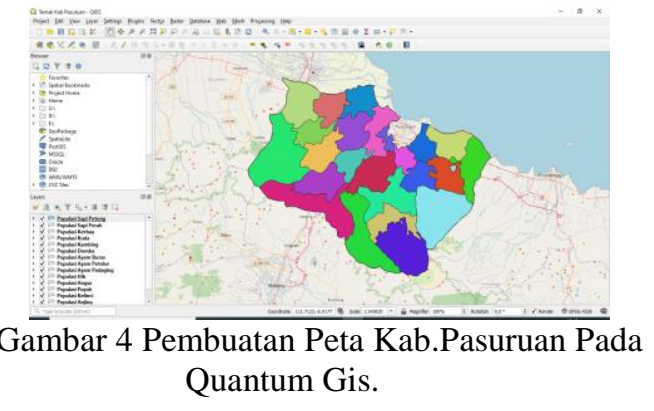

Pada gambar 4 merupakan tampilan pembuatan peta Kab.Pasuruan dengan ketentuan waran pada tiap kecamatan, adapun pembagian peta pada tiap-tiap kecamtan dengan atribut warna untuk pembeda pada beberapa kecamtan yang ada pada Kab.Pasuruan yang di tunjukan pada gambar 5 .

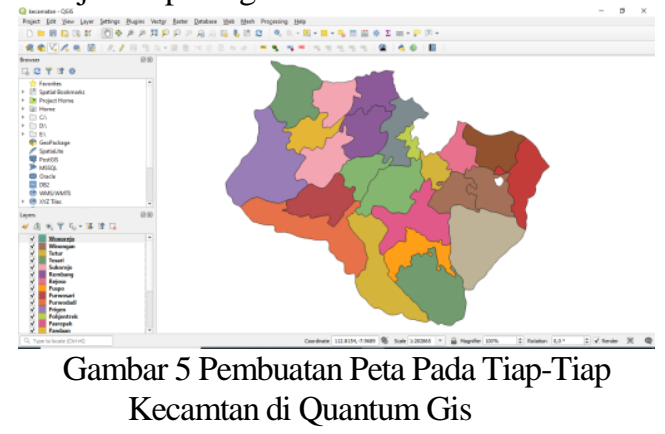

\subsection{Pengujian Webgis}

Pngujian webgis dilakukan untuk melihat hasil peta yang sudah dibuat melalui quantumgis lalu di export ke web dengan tampilan peta sesaui gambararan pada quantumgis di tunjukan pada Gambar 6.

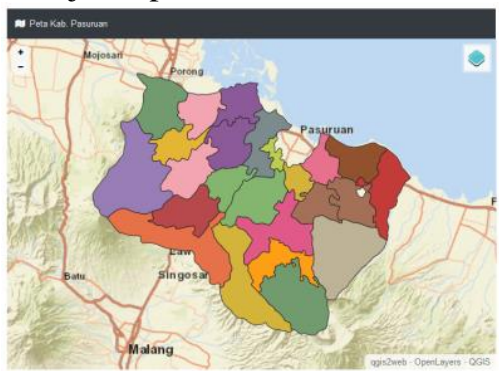

Gambar 6 Peta yang berhasil di export kedalam webgis. 


\subsection{Pengujian Fungsi Komponen}

Pengujian komponen dari atribut fungsi dengan pencarian data diantaranya Populasi ternak, Produksi ternak, dan budidaya dengan inputan pencarain sesuai data inputan yang di tunjukan pada gambar 7 .

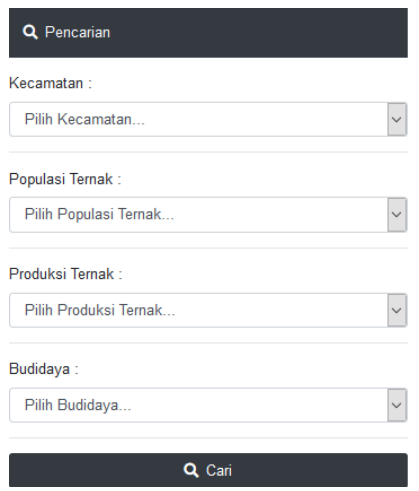

Gambar 7 atribut pencarian data populasi, produksi dan budidya.

Gambar 7 merupakan pencarian data atribut sesuai inputan diantaranya pencarian Populasi ternak, Produksi ternak, dan Budidaya dengan tampilan data sesuai inputan peta kecamtan dan pilihan data atribut sesuai pencarian yang di tunjukkan pada gambar 8 .

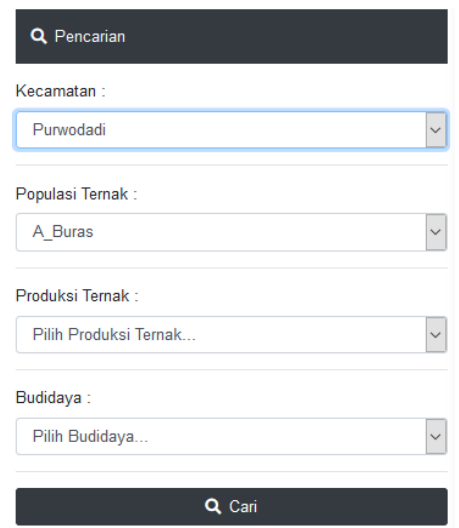

Gambar 8 pencarian data populasi ternak dengan ketentuan kecamatan.

Gambar 8 merupakan pencarian data atribut populasi ternak dengan contoh pencarian populasi Ayam buras dengan ketentuan kecamatan pada wilayah purwodadi Adapun data yang di temukan di tunjukkan pada gambar 9 .

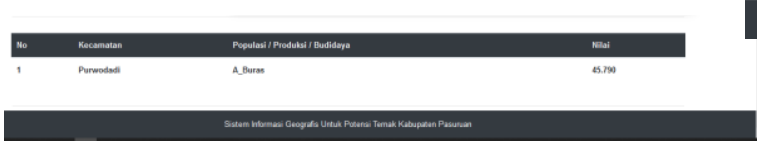

Gambar 9 hasil data pencarian populasi ternak pada daerah inputan kecamatan.

Gambar 9 merupakan hasil dari pencarian data populasi ternak pada daerah inputan kecamatan yang dipilih dan juga pilihan inputan dari data atribut populasi ternak dengan begitu menghasilkan data inputan sesuai yang dipilih.

\subsection{Gragik presentasi}

Grafik nilai presentasi merupakan nilai presentasi keseluruhan nilai data dari seluruh kecamatan dan juga seluruh komoditas yang ada pada Kab.Pasuruan dengan gaya presentasi nilai persenan dari tiap-tiap kecamtan yang mana daerah dengan nilai presentasi terbanyak pada populasi ternak, produksi ternak maupun budidaya. Kemudian adapun grafik batang untuk menunjukan hasil terbanyak populasi ternak, produksi ternak, maupun budidaya dengan menampilkan kecamatan mana yang mempunyai nilai terbanyak yang di tunjukan pada gambar 10.

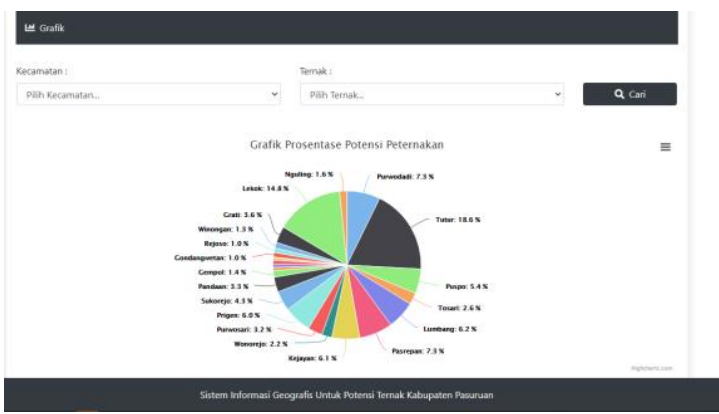

Gambar 10 grafik presentase

Pada grafik presentasi pada gambar 10 menjelaskan nilai presentasi dengan ketentuan pada kecamtan yang ada pada Kab.Pasuruan dengan total nilai terbesar yaitu pada kecamtan tutur dengan nilai presentasi $18,6 \%$ untuk keseluruhan nilai data dari populasi,produksi maupun budidaya yang ada pada kecamtan tutur, adapun tampilan grafik batang untuk menampilkan jumlah besarnya nilai data pada kecamtan tutur bisa di lihat pada gambar 11 berikut ini.

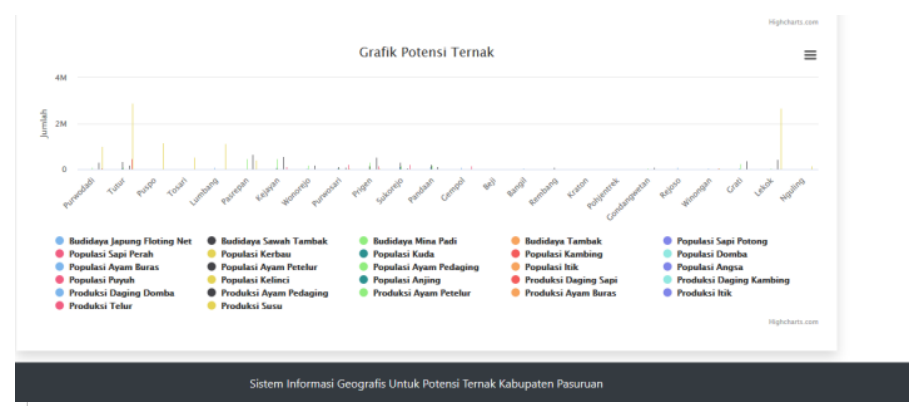

Gambar 11 grafik batang.

Pada grafik batang gambar 11 di atas merupakan tampilan untuk mellihat nilai data pada kecamatankecamtan yang ada pada Kab.Pasuruan dengan nilai yang terbesar yaitu terrdapat pada kecamatan tutur dengan nilai lebih dari $2 \mathrm{M}$ untuk kawasan terbesar populasi,produksi maupun budidaya yang ada pada Kab.Pasuruan. 
Tabel 1. Hasil Pengujian pada beberapa Web Browser.

\begin{tabular}{|l|c|c|c|}
\hline \multirow{2}{*}{\multicolumn{1}{|c|}{ Proses }} & \multicolumn{3}{c|}{ Web Browser } \\
\cline { 2 - 4 } & IE & MF & GC \\
\hline Tampilan Aplikasi & $B$ & $B$ & $B$ \\
\hline Proges Login & $B$ & $B$ & $B$ \\
\hline $\begin{array}{l}\text { Proses Input Data } \\
\text { Kecamatan }\end{array}$ & $B$ & $B$ & $B$ \\
\hline $\begin{array}{l}\text { Proges Input Data Potensi } \\
\text { Ternak. }\end{array}$ & $B$ & $B$ & $B$ \\
\hline $\begin{array}{l}\text { Proges Input Data Produksi } \\
\text { Ternak. }\end{array}$ & $B$ & $B$ & $B$ \\
\hline Proges Input data Budidaya & $B$ & $B$ & $B$ \\
\hline $\begin{array}{l}\text { Proges Halaman Detail Info } \\
\text { Kmoditas }\end{array}$ & $B$ & $B$ & $B$ \\
\hline Proges Grafik Nilai Data & $B$ & $B$ & $B$ \\
\hline
\end{tabular}

Keterangan :
IE :Internet Explorer
MF : Mozilla Firefox
$G C$ : Google Chrome
$B$ : Berhasil
G : Gagal

Pada hasil pengujian aplikasi dengan menggunakan 3 web browser yang berbeda, semua tampilan dan fungsi aplikasi dapat berjalan $100 \%$ pada 3 web browser yaitu Internet Explorer, Mozila Firefox, Google Chrome.

Tabel 2. Hasil Pengujian Sistem Fungsi.

\begin{tabular}{|c|c|c|c|}
\hline \multirow[b]{2}{*}{ Akses } & \multirow[b]{2}{*}{ Fungsi yang diuii } & \multicolumn{2}{|c|}{ Hasil } \\
\hline & & Berjalan & Tidak berialan \\
\hline \multirow{6}{*}{ User } & Cari keccamatan & $\checkmark$ & $x$ \\
\hline & Cari Populasi Ternak & $\checkmark$ & $x$ \\
\hline & Cari Produksi Ternak & $\checkmark$ & $x$ \\
\hline & Cari Budidava & $\checkmark$ & $x$ \\
\hline & Detail info komoditas & $\checkmark$ & $x$ \\
\hline & Nilai Grafik & $\checkmark$ & $x$ \\
\hline \multirow{5}{*}{ Admin } & $\begin{array}{c}\text { Tampilan Data } \\
\text { Kecamatan Halaman } \\
\text { Admin }\end{array}$ & $\checkmark$ & $x$ \\
\hline & $\begin{array}{c}\text { Tampilan Data } \\
\text { Potensi Ternak Pada } \\
\text { Halaman Admin }\end{array}$ & $\checkmark$ & $x$ \\
\hline & $\begin{array}{l}\text { Tampilan Data } \\
\text { Produksit Ternak Pada } \\
\text { Halaman Admin }\end{array}$ & $\checkmark$ & $x$ \\
\hline & $\begin{array}{l}\text { Tampilan Data } \\
\text { Budidava Pada } \\
\text { Halaman Admin }\end{array}$ & $\checkmark$ & $x$ \\
\hline & Logout & $\checkmark$ & $x$ \\
\hline
\end{tabular}

Keterangan

$\checkmark$ : tanda berhasil

$x$ : tanda tidak berhasil

\section{KESIMPULAN DAN SARAN}

\subsection{Kesimpulan}

Berdasarkan beberapa pengujian yang telah dilakukan didapatkan kesimpulan :

1. Pada tampilan webgis peta pada web menampilkan peta Kab.Pasuruan beserta peta atribut Kecamatan. Adapun peta kecamatan di olah dengan quantum gis mengasilkan digitasi peta atribut sesuai kecamatankecamatan yang ada pada Kab.Pasuruan, dan juga atribut pencarian.

2. Hasil pembuatan webigs pemetaan potensi ternak Kab.Pasuruan menunjukkan bahwa mengalokasikan tempat potensi ternak, produksi ternak dan juga budidaya pada tiap kecamatan Kab.Pasuruan ini sangatlah dinamis dengan adanya data pada tiap pencarian fungsi atribut sehingga bisa membantu masyarakat untuk melihat lokasi mana saja yang mempunyai peluang potensi ternak yang ada pada Kab.Pasuruan.

\subsection{Saran}

Berdasarkan penelitian yang telah dilakukan, maka penulis dapat memberikan saran-saran untuk pengembangan selanjutnya antar lain :

1. Dikembangkan melalui mobile agar lebih praktis dan lebih mdah di akses oleh semua kalangan.

2. Memperbanyak halaman data pencarian agar lebih di pahami masyarakat yang mengakses webgis ini.

\section{DAFTAR PUSTAKA}

[1] Ari, Z., 2017. SISTEM INFORMASI GEOGRAFIS SERVICE CENTER DI KOTA MALANG. JATI (Jurnal Mahasiswa Teknik Informatika), I(1), pp. 325-329.

[2] Pranoto, Y. A., Rokhman, M. M. \& Wibowo, S. A., 2018. APLIKASI PEMETAAN BERBASIS WEBSITE UNTUK PUSAT KESEHATAN. Jurnal MNEMONIC.

[3] Julkifli,2018.SISTEMINFORMASIGEOGRAFI SKECAMATAN WOJA KABUPATEN DOMPU NUSA TENGGARA BARAT. JATI(Jurnal Mahasiswa Teknik Informatika), II(1), pp. 144-152.

[4] Messy, A., 2019. SISTEM INFOMASI GEOGRAFIS PEMETAAN DAERAH PERKEBUNAN DAN KOMODITAS HASIL PANEN PROVINSI KALIMANTAN TENGAH. JATI (Jurnal Mahasiswa Teknik Informatika), III(1), pp. 165-172.

[5] Manurung,S.,2018.https://www.sgtgeomedia.co $\mathrm{m} /$.[Online]Availableat:https://www.sgtgeomedi a.com/detailpost/mengenal-leaflet-js-alternatifmembangun-peta-interaktif-berbasis-web-tanpagoogle-maps-api.

[6] Hasbiyatmoko, A., 2015. Format file di GIS? apa aja sih?. [Online] 
Available

http://latcoding.com/2015/12/26/tipe-data-di-

gis-apa-aja/.

[7] idtesis, 2014. idtesis.com. [Online] Available at: https://idtesis.com/pengertianpemetaan-geomapping-dalam-prosespengumpulan-data/.

[8] erdhana, 2019. erdhana12.blogspot.com. [Online]Availableat:https://erdhana12.blogspot. com/2019/10/perbedaan-data-spasial-nonspasial.html.

[9] Styawati, I. Y., 2020. Student Blog of Brawijaya University.[Online]Availableat:https://blog.ub.a c.id/ikayunistyawati/profil-pasuruan/potensidaerah/peternakan/ at:

[10] pasuruan, p. k., 2019. pasuruankab. [Online] Available at: www.pasuruankab.go.id [Accessed senin juni 2020].

[11] Supriyatno, H., 2019. harianbhirawa. [Online]. Availableat:https://www.harianbhirawa.co.id/pr oduksi-susu-di-kabupaten-pasuruan-melimpah/.

[12] Nasa, S., 2013. stockistnasa.com. [Online] Available at: https://stockistnasa.com/teknikbudidaya/ternak/. 